Revista Mídia e Cotidiano

ISSN: 2178-602X

Artigo Seção Temática

Volume 15, Número 3, set./dez. de 2021

Submetido em: 20/07/2021

Aprovado em: 25/09/2021

\title{
A "vacina chinesa de João Doria": a influência da disputa política-ideológica na desinformação sobre a vacinação contra a Covid-19
}

\section{The "João Doria's chinese vaccine": The influence of political-ideological dispute on disinformation about vaccination against Covid-19}

\section{La "vacuna china de João Doria": la influencia de la disputa político-ideológica en la desinformación sobre la vacunación contra Covid-19}

\author{
Ana Carolina Pontalti MONARI ${ }^{1}$ \\ Igor SACRAMENTO ${ }^{2}$
}

\section{Resumo}

Este artigo analisa a influência das disputas políticas e ideológicas na desinformação sobre a vacinação contra a Covid-19 no WhatsApp. Por meio das estratégias discursivas de legitimação para o conteúdo desinformativo (SOARES et al., 2021b), foram investigados nove vídeos que circularam no aplicativo de mensagens entre 30 de novembro de 2020 e 30 de janeiro de 2021 para compreender 1) quais seriam as características da desinformação sobre a vacina contra Covid-19 que circularam no aplicativo durante o período e 2) de que forma o discurso político-ideológico influenciou os conteúdos desinformativos sobre o imunizante. Em nosso estudo, observou-se que a desinformação sobre a vacinação contra a Covid-19 opera por meio de teorias da conspiração que se utilizam, sobretudo, de autoridades médicas para validar o seu discurso.

Palavras-chave: Vacinação. Covid-19. Estratégias de Legitimação. Disputas políticas e ideológicas.

\footnotetext{
1 Doutoranda do Programa de Pós-Graduação em Informação e Comunicação em Saúde (PPGICS), da Fundação Oswaldo Cruz (Fiocruz), e mestre em Comunicação pelo Programa de Pós-Graduação em Comunicação (PPGCOM), da Universidade Estadual Paulista (Unesp), onde também é graduada em Comunicação Social - Jornalismo. Bolsista de doutorado da Coordenação de Aperfeiçoamento de Pessoal de Nível Superior (CAPES). Integrante do Núcleo de Estudos em Comunicação, História e Saúde (NECHS - Fiocruz/UFRJ). E-mail: capmonari@gmail.com. ORCID: 0000-0002-7474-7903.

2 Doutor em Comunicação e Cultura pela Universidade Federal do Rio de Janeiro (UFRJ). Professor dos Programas de Pós-Graduação em Comunicação e Cultura, da UFRJ, e em Informação e Comunicação em Saúde, da Fundação Oswaldo Cruz (Fiocruz), onde também é coordenador. Bolsista de Produtividade em Pesquisa do CNPq. Líder do Núcleo de Estudos em Comunicação, História e Saúde (NECHS Fiocruz/UFRJ). E-mail: igorsacramento@gmail.com. ORCID: 0000-0003-1509-4778 .
} 


\begin{abstract}
This article analyzes the influence of political and ideological disputes on disinformation about Covid-19 vaccination on WhatsApp. Through discursive legitimation strategies for disinformation content (SOARES et al., 2021b), nine vídeos - circulated in the app between November 30, 2020 to January, 30, 2021 - were investigated to understand 1) what would be the disinformation characteristics about the Covid-19 vaccine that circulated in the app during the period and 2) how the political-ideological discourse influenced the disinformation contents about the vaccine. In our study, it was observed that disinformation about Covid-19 vaccination operates through conspiracy theories that use, above all, medical authorities to validate their discourse.
\end{abstract}

Keywords: Vaccination. Covid-19. Legitimation strategies. Political and ideological disputes.

\title{
Resumen
}

Este artículo analiza la influencia de las disputas políticas e ideológicas en la desinformación sobre la vacunación Covid-19 en WhatsApp. Mediante las estrategias de legitimación discursivas para contenidos no informativos (SOARES et al., 2021b), fueron investigados nueve videos que circularon en la app entre el 30 de noviembre de 2020 y el 30 de enero de 2021 para comprender 1) cuáles serían las características de la desinformación sobre la vacuna de Covid-19 que circuló en la aplicación durante el período y 2) cómo el discurso político-ideológico influyó los contenidos no informativos sobre el agente inmunizante. En nuestro estudio, se observó que la desinformación sobre la vacunación contra Covid-19 opera mediante teorías conspirativas que utilizan autoridades médicas para validar su discurso.

Palabras clave: Vacunación. Covid-19. Estrategias de legitimación. Disputas políticas e ideológicas.

\section{Introdução}

Em março de 2020, a Organização Mundial de Saúde (OMS) declarou que o mundo vive uma pandemia do novo coronavírus. Quase um ano depois, os desafios trazidos pelo Sars-CoV-2 ainda estão presentes na vida da população que, além de conviver com uma doença grave e mortal, também precisa lidar com os efeitos desencadeados por uma superabundância de informações - algumas precisas e outras não -, que dificultam o acesso das pessoas a fontes e orientações confiáveis quando necessitam. Este fenômeno é chamado pela OMS de infodemia e representa um sério risco para a saúde da população (OMS, 2020). 
Neste cenário de profusão de informações, diferentes atores disputam espaço na disseminação de narrativas sobre ciência. De acordo com Oliveira (2020a), esta é uma grande problemática, pois não se trata de falta de informações, mas de um conjunto de crenças consolidadas que vão de encontro aos valores estabelecidos em torno das instituições científicas como espaço de produção de dados, evidências e informações confiáveis para tomadas de decisão. Ela explica que esse conjunto de crenças está ligado a um processo político e ideológico voltado para a desconfiança sobre as instituições epistêmicas.

O fenômeno da infodemia compreende, além dos embates narrativos, o advento da desinformação. No Brasil, em especial, o conteúdo desinformativo sobre a Covid-19 tem sido impulsionado pelo discurso político e pela ausência de alinhamento entre as autoridades (RECUERO; SOARES, 2020). Desde o início da pandemia, o atual presidente do Brasil, Jair Bolsonaro, e os governadores dos Estados estão em lados opostos quando o assunto é o combate ao novo coronavírus. Baseado em uma lógica neoliberalista e respaldado pelas ações do ex-presidente americano Donald Trump, Bolsonaro centrou sua atuação contra a doença em três linhas: 1) relaxamento das medidas de isolamento social em prol da economia; 2) incentivo ao "tratamento precoce" com o uso de medicamentos sem comprovação científica; e 3) vacinação não obrigatória visando a liberdade individual.

Em relação a este último tópico, Bolsonaro acabou entrando em uma disputa narrativa pelo capital simbólico da primeira pessoa a ser vacinada no país com o governador de São Paulo, João Doria $(G 1,2020)$. O político paulistano ficou conhecido na mídia por ser um dos principais opositores das medidas de combate à Covid-19 implementadas pelo governo federal, optando pelo isolamento social em seu estado e firmando parceria com a farmacêutica chinesa Sinovac para a produção da vacina CoronaVac no Instituto Butantã, em São Paulo. O governo federal, por outro lado, estabeleceu acordo com a farmacêutica AstraZeneca e a Universidade de Oxford para a compra de lotes e transferência de tecnologia da Covishield, que será produzida na Fundação Oswaldo Cruz (Fiocruz), no Rio de Janeiro (Fiocruz, 2020). 
Com os bons resultados apresentados pela CoronaVac nos testes clínicos no fim de 2020, Doria e Bolsonaro acirraram o embate político sobre a utilização ou não deste medicamento em suas redes sociais digitais e seus discursos passaram a refletir um uso da ciência de acordo com suas próprias crenças e ideologias (MONARI; SANTOS; SACRAMENTO, 2020). Parte desses argumentos acabaram sendo representados em desinformações que circularam neste mesmo período, sobretudo, no WhatsApp.

Diante disso, o objetivo deste trabalho é analisar a influência das disputas políticas e ideológicas na desinformação sobre a vacina contra a Covid-19 no WhatsApp. Para isso, serão investigadas mensagens que circularam no aplicativo de mensagens pessoais durante o período de 30 de novembro de 2020 a 30 de janeiro de 2021, ou seja, um mês antes da primeira pessoa ser vacinada contra a doença fora dos testes clínicos no Brasil (BBC, 2021).

Este estudo parte de duas questões principais: 1) quais são as características da desinformação sobre a vacina contra Covid-19 que circularam no WhatsApp durante o período? e 2) de que forma o discurso político-ideológico influencia os conteúdos desinformativos sobre o imunizante?

\section{WhatsApp, desinformação e estratégias discursivas}

O WhatsApp é uma plataforma de mídia social, que permite aos usuários espaços ilimitados para armazenar ferramentas com o intuito de organizar, promover e transmitir seus pensamentos, opiniões, comportamentos e demais conteúdos para outras pessoas (SOUZA; ARAÚJO; PAULA, 2015). Em outras palavras, é um espaço de interação entre usuários, que reflete tanto as redes sociais quanto os discursos que permeiam a sociedade.

O aplicativo de mensagens é composto por um design de rede privada com criptografia ponta-a-ponta, porém as estruturas de rede decorrentes de suas apropriações sociais no Brasil o transformaram em uma poderosa e valiosa ferramenta de disseminação de informações para grandes públicos. $\mathrm{O}$ fato de oferecer o serviço de mensagens mobile sem custos de internet acabou atraindo inúmeras pessoas que não têm acesso à rede de outro modo, o que contribuiu para o aplicativo alcançar 120 milhões de usuários ativos em 2018 (SANTOS et al., 2019). Diante disso, é possível depreender que o WhatsApp 
tem um papel fundamental na disseminação de desinformação (NEWMAN et al., 2020), sendo, inclusive, um dos grandes responsáveis pelo espalhamento de conteúdos desinformativos nas eleições presidenciais de 2018 no Brasil (REIS et al., 2020).

Esta ferramenta, bem como outras mídias sociais, tem mecanismos que contribuem para a forma como a desinformação é produzida e difundida para o público. Ou seja, o uso do WhatsApp é influenciado por suas estruturas tecnológicas, que são os modos pelos quais as pessoas se engajam com os mesmos (BOYD, 2010). No caso do aplicativo de mensagens pessoais, esses recursos dão ao usuário a percepção de privacidade, afetando as suas ações e interações com outros usuários. Isso também traz uma particularidade para a desinformação que circula neste ambiente, pois ela não pode ser rastreada ou verificada publicamente por agências de fact-checking (SOARES et al., 2021a).

Neste trabalho, entende-se desinformação a partir do conceito elaborado por Wardle \& Derakshan (2017), que o elenca como um dos três elementos da desordem informacional. Segundo os autores, esta noção seria dividida em disinformation (informação falsa que é criada deliberadamente para prejudicar uma pessoa, grupo social, organização ou país), misinformation (informação falsa, mas não criada com a intenção de causar prejuízo) e mal-information (informação que é baseada na realidade, porém usada para causar prejuízos para uma pessoa, organização ou país).

Baines e Elliott (2020, p.12) afirmam que a má-informação requer "intenção e equivalência e muitas vezes envolve uma redefinição do valor de verdade da informação para fins enganosos". Portanto, misinformation é informação imprecisa, aberta a múltiplas compreensões e usos; disinformation é a informação deliberadamente enganosa, com intenção de enganar ou não; e mal-information é a informação sensível (verdadeira) que é estrategicamente usada para causar vantagem.

Para que a desinformação seja disseminada, no entanto, são necessárias estratégias discursivas para legitimar e aumentar a visibilidade dessas mensagens (SOARES et al., 2021b). De acordo com a análise crítica do discurso (FAIRCLOUGH, 2001), as estratégias textuais estão associadas às práticas discursivas, sendo estas relacionadas às práticas socioculturais. É possível afirmar, portanto, que as estratégias discursivas são 
usadas para estabelecer um determinado enquadramento de um discurso, cujas estruturas do texto são concebidas para legitimá-lo.

Wodak (2001) trabalha com a ideia de que a estratégia discursiva é uma prática de negociação de poder. De acordo com a autora, o conceito pode ser definido como um conjunto mais ou menos intencional de práticas, incluindo as práticas discursivas, que visam atingir um propósito social, político, psicológico ou linguístico.

Van Leeuwen (2007), por outro lado, defende a noção de estratégias de legitimação para as práticas discursivas, sendo estas utilizadas para reconhecer e validar certas práticas sociais e enquadramentos discursivos. De acordo com ele, há quatro modos de legitimação: a) autorização, quando o texto remete a uma autoridade pessoal (indivíduo com posição ou autoridade institucional) ou impessoal (tradição, costume ou lei); b) avaliação moral, quando a legitimação está baseada em sistema de valores de uma sociedade ou grupo; c) racionalização, quando a validação está amparada no conhecimento, argumentação ou cognição; e d) mythopoesis, em que a legitimação é feita pela construção de narrativas ou histórias, seja de cunho moral ou que visam um alerta.

Neste estudo, optou-se pela análise de três estratégias discursivas de legitimação construídas por Soares et al. (2021b) a partir do framework da análise crítica do discurso (FAIRCLOUGH, 2001). Essas categorias são:

1)Uso de opinião (O): é a estratégia relacionada à forma como a desinformação é apresentada, sendo considerada tanto a opinião pessoal quanto a reprodução de opiniões de terceiros. Ela é uma estratégia argumentativa de validação de um discurso, uma vez que o locutor expressa sua concordância com ele. A opinião pode utilizar diversos modos de legitimação, mas geralmente foca-se na avaliação moral ou racionalização;

2) Uso de autoridades (A): é uma estratégia que se utiliza da reputação de um indivíduo ou organização. Seu uso aparece como uma forma de legitimação do discurso em razão do indivíduo ou instituição utilizados para dar credibilidade ao discurso. Pode ser uma estratégia de perspectivação (construção da legitimação a partir da proximidade do locutor com a questão) ou de intensificação (potencializa e fortalece a mensagem); 
Call to action (CA): serve para motivar usuários a realizar determinada ação - por exemplo, o compartilhamento de mensagens. É uma estratégia de intensificação da mensagem (agrega senso de urgência) e de perspectivação.

\section{Estratégias discursivas de legitimação da desinformação sobre a vacina contra Covid-19}

Para analisar a influência das disputas políticas e ideológicas na desinformação sobre a vacina contra Covid-19, optou-se por uma amostra de estudo não probabilística (por conveniência), sendo que as mensagens foram coletadas entre 30 de novembro de 2020 e 30 de janeiro de 2021 por um dos autores em seu próprio aplicativo de WhatsApp mediante solicitação a amigos e familiares. Durante o período - que corresponde ao mês anterior à data da primeira pessoa imunizada no Brasil fora dos testes clínicos (BBC, 2021) -, foram coletadas 29 mensagens. Em virtude da limitação de espaço e compreendendo que as formas visuais apresentam maior alcance, além de serem mais persuasivas que conteúdos textuais (WARDLE; DERAKSHAN, 2017), optou-se por analisar apenas os formatos audiovisuais - totalizando nove vídeos.

Os conteúdos foram submetidos às estratégias discursivas de legitimação para o conteúdo desinformativo, que foram sistematizadas por Soares et al. (2021b) com base no framework da análise crítica do discurso (FAIRCLOUGH, 2001). Os dados podem ser conferidos abaixo ${ }^{3}$.

Tabela 1 - Conteúdos desinformativos e suas estratégias discursivas de legitimação

$\begin{array}{ccc}\begin{array}{c}\text { Data de recebimento da } \\ \text { mensagem no } \text { whatsapp }\end{array} & \text { Conteúdo desinformativo } & \begin{array}{c}\text { Estratégia discursiva de } \\ \text { legitimação }\end{array} \\ 01 / 12 / 2020 & \begin{array}{c}\text { Dra. Raíssa Soares aborda } \\ \text { realidades do público e do } \\ \text { privado. }\end{array}\end{array}$

3 Os conteúdos dos vídeos foram apresentados de forma reduzida em virtude do espaço. No entanto, eles foram armazenados na íntegra no Google Drive pelos autores, podendo ser conferidos pelo link: https://bit.ly/3urYf15. A autoria da mensagem foi preservada. 
Tabela 1 - Conteúdos desinformativos e suas estratégias discursivas de legitimação

(continuação)

$01 / 12 / 2020$

Enfermeiro de Cabo Frio (RJ)

$\mathrm{O}, \mathrm{A}, \mathrm{CA}$

comenta sobre suposta morte

de médico em virtude da vacina

contra Covid-19.

$03 / 12 / 2020$

$05 / 12 / 2020$

$05 / 12 / 2020$

$09 / 12 / 2020$

Dra. Christine Northrup traça

$\mathrm{O}, \mathrm{A}$

relações entre a vacina contra

Covid-19 e alterações de DNA

humano.

Homem não identificado faz

$\mathrm{O}, \mathrm{CA}$

questionamentos sobre o

isolamento social.

Dr. Marcelo Frazão ${ }^{4}$ comenta

$\mathrm{O}, \mathrm{A}$

que a vacina contra Covid-19

pode alterar o código genético.

Dr. Anthony Wong argumenta

$\mathrm{O}, \mathrm{A}$

$24 / 12 / 2020$

sobre a execução rápida dos

testes clínicos das vacinas

contra Covid-19.

Dr. Paulo Porto, em entrevista

$\mathrm{O}, \mathrm{A}$

para a jornalista Leda Nagle, comenta sobre os possíveis

riscos relacionados à vacina

contra Covid-19.

$06 / 01 / 2021$

Pastor Silas Malafaia questiona

$\mathrm{O}, \mathrm{A}, \mathrm{CA}$

a rapidez dos testes clínicos da

vacina contra Covid-19.

4 Embora se apresente com o título de doutor, Marcelo Frazão é engenheiro. Ele não possui registro profissional no Conselho Regional de Medicina de São Paulo (Cremesp) e seu currículo na plataforma Lattes não apresenta nenhuma formação que comprove sua suposta titularidade acadêmica (COSTA, 2020). 
Tabela 1 - Conteúdos desinformativos e suas estratégias discursivas de legitimação

(continuação)

$07 / 01 / 2021$

Médico não identificado afirma

A

que vacinas podem alterar o

código genético.

Fonte: elaborado pelos autores (2021).

Nos vídeos analisados, observou-se que a maioria das mensagens (cinco, no total) empregou as estratégias do uso de opiniões $(\mathrm{O})$ e autoridades $(\mathrm{A})$ para legitimar o seu discurso. Em seguida, outros dois vídeos apontaram para o uso de opinião (O), autoridades (A) e call to action (CA) como táticas discursivas.

\section{Uso de opinião (O) e uso de autoridades (A)}

Em cinco dos nove vídeos investigados neste estudo, a desinformação é apresentada por meio da opinião de um especialista (médico). Seus pareceres, enquanto médicos (ou supostos médicos), ganham legitimidade em virtude da própria instituição que esses indivíduos representam. Diante disso, frases como "não temos vacina verdadeira", "não somos cobaias" e a "vida tem que voltar ao normal" (01/12/2020 - Dra. Raíssa Soares) acabam sendo intensificadas em razão da posição ocupada por esses peritos.

As técnicas de perspectivação e intensificação, que estão presentes na estratégia discursiva de legitimação do uso de autoridades (SOARES et al., 2021b), são reforçadas pelos médicos e pretensos médicos, graças a construções argumentativas com supostos dados ("leva-se 15 anos para fabricar uma vacina" - 05/12/2020 - e "recomendação da NHS" - 24/12/2020) e conselhos ("não aconselho vocês a fazer isso [se vacinar]" 05/12/2020).

O desempenho da opinião também parte de uma legitimação pela avaliação moral e pela mythopoesis, pois há a construção de narrativas visando alertar a população sobre possíveis perigos (vacina pode ocasionar alterações do material genético - 03 e 05/12/2020; e vacina da Pfizer mata duas pessoas e deixa quatro com paralisia facial 24/12/2020). 
O emprego de teorias da conspiração é evidente nesta categoria em frases como "vacina foi feita para reduzir a população mundial" (05/12/2020) e "China estaria dando a $3^{\text {a }}$ dose da CoronaVac" (09/12/2020). Em relação à esta última afirmação, é válido mencionar que o vídeo (09/12/2020) em que o médico pediatra e toxicologista Anthony Wong aborda essa questão traz o argumento conspiratório de que um terço dos voluntários da CoronaVac ainda não tinham tomado a $2^{\mathrm{a}}$ dose do imunizante, o que inviabilizaria a comprovação da eficácia da pesquisa clínica e, respectivamente, a imunização desse grupo.

Os dados apontam para o uso dos termos "China" e "comunista" como formas de combate aos opositores do atual governo do presidente Jair Bolsonaro (SOARES et al., 2021a). Frases como "essa vacina é uma pauta comunista" (05/12/2020), "governador de São Paulo, esse comunista" (05/12/2020) e "você tem uma vacina chinesa que tem várias inconformidades que precisam ser solucionadas" (24/12/2020) ilustram esse fato.

Conforme abordado em outro trabalho (SACRAMENTO; MONARI; CHEN, 2020), no início da pandemia houve a disseminação de peças desinformativas com a ideia de um "vírus chinês", sendo esta uma possível estratégia de guerrilha biológica promovida pela China para uma possível conquista mundial. Com os dados obtidos neste estudo, é possível perceber que esse conflito de alteridade entre ocidentais e orientais continua o mesmo quase um ano depois, mas, desta vez, o foco é voltado para a vacina, criando uma ideia xenófoba de suspeição do imunizante em razão da localização da farmacêutica responsável por ele.

Por outro lado, é interessante notar a maneira como a ciência é empregada discursivamente nestes conteúdos. No vídeo (01/12/2020) em que a Dra. Raíssa Soares aborda supostas diferenças entre as realidades de saúde pública e privada, a médica ressalta a necessidade de que a vacina contra Covid-19 passe por todos os testes clínicos e recomenda que as pessoas só tomem o imunizante após "estudos comprovados", mas não diz o mesmo em relação ao "tratamento precoce". Ela diz que o "remédio de piolho" (ivermectina) é ótimo para os momentos em que as pessoas "aglomeraram”. Não há, entretanto, pesquisas científicas que comprovem a eficácia da ivermectina como recurso terapêutico para Covid-19, apontando, portanto, para um uso interessado da ciência 
(MONARI; SANTOS; SACRAMENTO 2020; MONARI, 2020), em que o discurso científico só é utilizado quando atende a determinados propósitos - no caso, negar a vacina e promover o "tratamento precoce".

\section{Uso de opinião (O), uso de autoridades (A) e call to action (CA)}

Nesta categoria, que contabiliza dois vídeos, a apresentação da desinformação é feita novamente por meio da opinião de especialistas (pretenso enfermeiro e pastor evangélico), contudo há ainda o chamado para ação (call to action), que serve para motivar os usuários a realizar determinado comportamento. Com solicitações de “compartilhem esse vídeo" (01/12/2020 - enfermeiro de Cabo Frio-RJ), "assista esse vídeo até o fim" (06/01/2021) e "se você acha importante... compartilha com outros" (06/01/2021), os conteúdos audiovisuais empregam estratégias de intensificação, que agregam senso de urgência para o público (SOARES et al., 2021b).

Os dados analisados neste grupo também apontam para a desinformação como uma forma das pessoas minimizarem estratégias de saúde e não seguirem evidências científicas em virtude de suas visões políticas (SOARES et al., 2021a). Esse fato é ilustrado, por exemplo, com o suposto comparativo que envolve a ingestão de ivermectina e baixos índices de casos de Covid-19 no continente africano (06/01/2021) feito pelo pastor Silas Malafaia.

A transformação da vacinação contra Covid-19 de questão de saúde para questão política está presente nos dois vídeos investigados. Isso fica evidente quando o suposto enfermeiro de Cabo Frio (01/12/2020) diz que "Doria, esse corrupto de São Paulo, quer obrigar as pessoas a serem vacinadas", remetendo às declarações do governador paulista sobre a possibilidade de obrigar a população do Estado a tomar a vacina (G1, 2020) e a questão da liberdade do indivíduo de se vacinar ou não - algo defendido pelo atual presidente e que reflete a polarização política estabelecida no país (RECUERO; SOARES, 2020). Outro elemento que contribui para esse fato é o pedido feito por Malafaia (06/01/2021), quando ele afirma "vamos parar com essa politicagem baixa" em contraposição à tese de que a vacinação no Brasil estaria atrasada e reforçando a ideia de 
que o imunizante feito pelo Butantã em parceria com a Sinovac seria inferior, uma vez que supostamente não existiriam países desenvolvidos utilizando a droga.

Os dados expostos nas demais categorias não diferem das duas apresentadas anteriormente neste estudo. Nestes dois segmentos (uso de autoridades e uso de opinião e call to action), entretanto, a questão da liberdade do indivíduo fica bem evidente, principalmente no vídeo de 05/12/2020, quando o locutor (não identificado) utiliza sua opinião para validar argumentos morais.

\section{Discussão}

Os conteúdos analisados neste trabalho evidenciam que a desinformação sobre a vacinação contra a Covid-19 opera por meio das teorias da conspiração. Em, pelo menos, seis vídeos, há afirmações conspiratórias de que o imunizante alteraria o código genético humano (07/01/2021), que a presença de metais tóxicos na vacina transformaria o corpo humano em uma antena com sinal 5G (3/12/2020) e que ela seria capaz de tirar dados biométricos e armazená-los na nuvem (3/12/2020) - fato que estaria ligado à Fundação Bill e Melinda Gates.

Aupers (2012) afirma que a cultura conspiratória não é um antídoto da modernidade, mas uma radical e generalizada manifestação da desconfiança, que está embutida em uma lógica cultural da própria modernidade. Segundo ele, em sua forma tradicional, as teorias da conspiração trabalham com a ideia de "nós" versus "eles", porém, na atualidade, elas focam menos nesse "outro imaginário" e mais em paranoias sobre as instituições epistêmicas.

O inimigo, portanto, estaria "dentro do sistema" e seria representado por políticos, pela indústria farmacêutica, pelas multinacionais, pelos laboratórios e pelos cientistas. Sendo assim, esses conteúdos conspiratórios contestariam a autoridade epistêmica da ciência e resistiram ao regime de verdade em que a ciência tem o poder legítimo de definir, descrever e explicar os domínios da realidade (HARAMBAM; AUPERS, 2015).

É importante ressaltar que parte da crise que a ciência está instalada na contemporaneidade é proveniente da própria comunicação da ciência. Oliveira (2020b) explica que, com a chegada das plataformas digitais, o conhecimento científico, que antes 
ficava nas mãos dos jornalistas, pode ser agora distribuído pelos próprios pesquisadores em suas redes. Contudo, essa ampla divulgação tem entraves impostos pelas próprias plataformas, que trabalham com algoritmos, e pela chegada de diferentes atores que disputam a informação científica.

Para além disso, esse conflito do nós versus eles também é apropriado por políticos com aproximações populistas (PARZIANELLO, 2020), pois estes trabalham com o antagonismo entre povo e elite, em que os membros da elite seriam corruptos, conspiratórios e indispostos a atender às demandas do povo (MEDE; SCHÄFER, 2020). Essa narrativa de confronto entre o populismo e a elite é utilizada pelo presidente Bolsonaro em diversos momentos da questão da vacinação contra Covid-19 (G1, 2020) e parte desses argumentos pode ser encontrada na desinformação sobre o assunto, especialmente em relação a Doria.

Nas peças desinformativas investigadas, o governador paulista faria parte dessa elite, que opera junto a outros membros (cientistas, por exemplo), para impedir a opção de escolhas pessoais do indivíduo. Segundo Harambam \& Aupers (2015), os adeptos das teorias da conspiração clamam pela necessidade de escolhas pessoais e para que haja uma discussão aberta com experts sobre os tópicos que desejam analisar ao invés de serem falados sobre o que fazer de forma autoritária.

Doria, ao dizer que a vacina contra a Covid-19 seria compulsória em São Paulo, estaria, portanto, contrariando essa possibilidade de decisão. Bolsonaro, por outro lado, ao afirmar que o imunizante seria disponibilizado à população de forma não obrigatória visando à liberdade do indivíduo de escolher se vacinar ou não iria a favor dessa ideia e, por isso, atenderia às demandas do povo.

Embora as teorias da conspiração se valham do descrédito das instituições epistêmicas, no caso analisado por este estudo, a autoridade médica acabou sendo usada para validar os argumentos antivacina. Ou seja, quando o conteúdo vai ao encontro de suas crenças, o discurso proferido por um médico - que supostamente faria parte dessa elite corrupta e conspiratória - acaba sendo um reforço do argumento, dando credibilidade e respaldo a ele (OLIVEIRA, 2020b). 
Essas dinâmicas informacionais balizam o que Jayson Harsin (2015) chama de regime de pós-verdade, que amplamente explora novas "liberdades" para participar, produzir e expressar, bem como consumir, difundir e avaliar discursos e experiências pessoais, não necessariamente baseados em evidências científicas, como verdadeiros. Esses desenvolvimentos correspondem ainda àquilo que Harsin (2015) nomeia póspolítica e pós-democracia, em que questões, discursos e agências para a mudança sociopolítica permanecem restritos, apesar da habilitação de uma nova gama de participação cultural e pseudopolítica em torno, entre outras coisas, da verdade. O regime de pós-verdade surge de estratégias pós-políticas/pós-democráticas comuns às sociedades contemporâneas, onde atores políticos especialmente ricos em recursos tentam usar o conhecimento analítico de dados para gerenciar o campo de aparência e participação, por meio da atenção e do afeto. O regime de pós-verdade, particularmente como experiência afetiva, está no centro das lutas pelo poder epistêmico. Os desafios enfrentados ao fazêlo são o objeto da análise aqui realizada. Esta investigação enfoca as dimensões-chave de duas posições epistemológicas desenvolvidas dentro da transformação do regime de verdade contemporâneo. Em primeiro lugar, a discussão leva em conta a afirmação fundacionalista de que o mundo é vivenciado diferencialmente pelas lentes da experiência pessoal e que, como resultado, as pessoas conhecem o mundo de um ponto de vista distinto e epistemologicamente superior. Isso é seguido por um exame das perspectivas anti-fundacionalistas que enfatizam que, como o conhecimento se origina de locais sociais específicos, o que pode ser conhecido é sempre parcial e, como tal, não pode ser reduzido a uma verdade universal e singular. As principais suposições associadas a cada posição materializam-se nas lutas atuais de pós-verdade sobre o poder epistêmico concernente, em primeiro lugar, a quem pode fazer reivindicações válidas e, em segundo lugar, o que pode ser legitimamente reivindicado.

Surge uma visão de que não há nenhuma realidade externa "verdadeira" a ser descoberta por um sujeito cognoscente autônomo; que há apenas uma pluralidade de perspectivas parciais que são cultural e historicamente contingentes; que produzir conhecimento com uma premissa de objetividade obscurece o funcionamento do poder em assegurar versões da "verdade"; e que, se a verdade é um efeito do discurso, devemos 
analisar a variedade de narrativas ou representações que constituem nossas experiências como se fossem reais. Nesse sentido, a pós-verdade passa a ser definida como um adjetivo relacionado a ou denotando circunstâncias em que fatos objetivos são menos influentes na formação da opinião pública do que apelos à emoção e à crença pessoal.

Aquilo que pode ser entendido como evidência factual é, assim, colocado em disputa, introduzindo um padrão muito diferente para medir a verdade das reivindicações. O resultado é um nivelamento das posições a partir das quais a verdade emana uma "democratização da epistemologia" (SISMONDO, 2017), que em seu coração é movido por uma suspeita de "elites", autoridades estabelecidas e minorias que parecem ter recebido uma posição privilegiada que é injustificada.

A retórica da pós-verdade exige status de autoridade a ser devolvido a indivíduos "normais", que são incitados a falar a verdade de sua própria experiência individual através das lentes do que é classificado como sendo de bom senso. Esta conexão entre verdade e experiência ressoa com debates que têm destaque na epistemologia contemporânea. Há uma intensa presença social de ativismos que buscam justiça com base na experiência; são reivindicações baseadas no sensível, na crença, na afinidade e na identificação pessoais.

Existe, como estamos observando, uma afinidade entre o populismo e as práticas de comunicação da pós-verdade, com o populismo se opondo aos princípios fundamentais da comunicação democrática, nomeadamente a necessidade de um debate fundamentado e baseado em factos, tolerância e solidariedade - princípios essenciais para uma vida pública viável nas sociedades atuais.

\section{Considerações finais}

Por meio da análise da desinformação sobre a vacina contra a Covid-19, pode-se depreender que os conteúdos falsos apresentaram características específicas, tais como o grande uso de opiniões e reforços de autoridade, em especial a médica. Baseados, sobretudo, em teorias da conspiração, os nove vídeos investigados trazem a concepção da pandemia como conspiração e que as medidas para combatê-la seriam, na verdade, 
estratégias para minar ou diminuir o atual presidente do Brasil, Jair Bolsonaro (SOARES et al., 2021a).

O discurso político e ideológico também influencia os conteúdos desinformativos sobre o imunizante, principalmente a partir do embate entre o presidente e os governadores dos estados, em especial João Doria. Isso fica evidente não apenas pelo emprego da lógica do "nós" (povo) versus "eles" (elite), mas também na associação xenófoba entre o vírus e a China (SACRAMENTO; MONARI; CHEN, 2020), que foi trasladada para a questão da vacina desenvolvida contra a doença.

Diante de todo o exposto, é inegável o fato de que a circulação da desinformação nas plataformas digitais (em especial, o WhatsApp) está inserida em um contexto populista e de crise epistêmica, que é reflexo da passagem de um regime de verdade baseado na confiança nas instituições para outro regulado pela crença individual e pela experiência pessoal, o que garante voz a movimentos conspiratórios (OLIVEIRA, 2020b).

Este sentimento anti-elitista do populismo contemporâneo não visa apenas os políticos, mas também outros representantes do suposto sistema - incluindo cientistas e instituições acadêmicas. No entanto, as especificidades desse populismo relacionado à ciência ainda não foram conceituadas. Pretendemos fazer isso, integrando estudos sobre populismo político, a "virada participativa" e epistemologias alternativas. Propomos conceituar o populismo relacionado à ciência como um conjunto de ideias que sugere que há um antagonismo moralmente carregado entre pessoas comuns (supostamente) virtuosas e uma elite acadêmica (supostamente) não virtuosa, e que esse antagonismo se deve ao fato de a elite alegar ilegitimamente que as pessoas não têm soberania de tomada de decisão relacionada à ciência e nem de falar a verdade. Assim, a ciência passa a ser suspeita, e a verdade é relativa.

Trata-se de um populismo epistemológico que se estabelece por meio de uma variedade de técnicas retóricas e pressupostos: a afirmação de que as opiniões individuais baseadas na experiência em primeira mão são muito mais confiáveis como forma de conhecimento do que aquelas geradas por teorias e estudos acadêmicos; a valorização de tipos específicos de experiência como fontes particularmente confiáveis de conhecimento 
legítimo e a extensão dessa autoridade de conhecimento a questões não relacionadas; o privilegiamento da intensidade emocional como indicador da confiabilidade das opiniões; o uso do discurso de inflexão populista para descartar outros tipos de conhecimento como elitistas e, portanto, ilegítimos; e, finalmente, o apelo ao "bom senso" como um trunfo para encerrar qualquer discussão. Esse "bom senso" é frequentemente estruturado por uma verdade emocional, por sentimentos e crenças compartilhados, e não necessariamente baseada em evidências científicas.

Por fim, é importante ressaltar que este estudo apresenta limitações. Para além da amostra por conveniência, que limitou o número de mensagens recebidas para a análise, o recorte utilizado (vídeos) retrata apenas uma parte da dimensão composta pela desinformação, que também aparece sob a forma de textos e imagens. Compreende-se, portanto, a necessidade de outros estudos sobre o tema para entender e aprofundar o conhecimento sobre esse assunto.

\section{Referências}

AUPERS, Stef. "Trust no one": modernization, paranoia and conspiracy culture. European Journal of Communication, v. 27, n. 1, p. 22-34, 2012.

BAINES, Darrin; ELLIOT, Robert J. R. Defining misinformation, disinformation and malinformation: an urgente need for clarity during the COVID-19 infodemic. University of Birmingham Discussion Paper, n. 20-06, 2020.

BBC. Enfermeira de SP é a $1^{\text {a }}$ vacinada do Brasil. BBC, 2021. Disponível em: https://bbc.in/3e1aYBv. Acesso em: 14 abr. 2021.

BOYD, Danah. Social network sites as networked publics: affordances, dynamics, and implications. In: PAPACHARISSI, Z. (ed.). A networked self: identity, community, and culture on social network sites. Abingdon: Routledge, 2010. p. 39-58

COSTA, Samuel. \#Verificamos: Áudio do WhatsApp usa dados falsos para dizer que ‘coronavírus não mata ninguém'. Agência Lupa, 27 out. 2020. Disponível em: https://bit.ly/3kzjsUE. Acesso em: 22 set. 2021.

FAIRCLOUGH, Norman. Discurso e mudança social. Brasília: Editora UnB, 2001

FIOCRUZ. Covid-19: Fiocruz firmará acordo para produzir vacina da Universidade de Oxford. Fiocruz, 27 jun. 2020. Disponível em: https://bit.ly/3uSgygk. Acesso em: 07 abr. 2021.

G1. Veja a cronologia da disputa entre Bolsonaro e Doria em torno da vacina contra a Covid-19. G1, 2020. Disponível em: https://glo.bo/3w99CwG. Acesso em: 07 abr. 2021. 
HARAMBAM, Jaron; AUPERS, Stef. Contesting epistemic authority: conspiracy theories on the boundaries of Science. Public Understanding of Science, v. 24, n. 4, p. 466-480, 2015.

HARSIN, Jayson. Regimes of posttruth, postpolitics, and attention economies.

Communication, Culture and Critique, v. 8, n. 2, p. 327-333, 2015.

MEDE, Niels; SCHÄFER, Mike. Science-related populism: conceptualizing populist demands toward science. Public Understand of Science, v. 29, n. 5, p. 473-491, 2020.

MONARI, Ana Carolina Pontalti; SANTOS, Allan; SACRAMENTO, Igor. Covid-19 and (hydroxy)chloroquine: a dispute over scientific truth during Bolsonaro's weekly Facebook live streams. Journal of Science Communication, v. 19, n. 7, A03, 2020.

MONARI, Ana Carolina Ponalti. A mídia e a ciência que me "servem": o reforço da autoridade jornalística e científica nas postagens do Twitter de Jair Bolsonaro. In: PAULINO, Rita; RODRÍGUEZ-HIDALGO, Claudia. (Orgs.). Jornalismo, sociedade e pandemia. Aveiro: Ria Editorial, 2020. p. 196-218.

NEWMAN, Nic; FLETCHER, Richard; SCHULZ, Anne; ANDI, Simge; NIELSEN, Rasmus Kleis. Reuters Institute Digital News Report 2020. Oxford: Reuters Institute, Oxford University, 2020

OLIVEIRA, Thaiane. Como enfrentar a desinformação científica? Desafios sociais, políticos e jurídicos intensificados no contexto da pandemia. Liinc em Revista, v. 16, n. 2, e5374, dez. 2020a.

OLIVEIRA, Thaiane. Desinformação científica em tempos de crise epistêmica: circulação de teorias da conspiração nas plataformas de mídias sociais. Fronteiras, v. 22, n. 1, p. 21-35, $2020 b$.

ORGANIZAÇÃO MUNDIAL DE SAÚDE - OMS. Benin goes on digital offensive against COVID-19. OMS, 09 abr. 2020. Disponível em: https://bit.ly/3wYHrkk. Acesso em: 09 fev. 2021.

PARZIANELLO, Geder Luis. O governo Bolsonaro e o populismo contemporâneo: um antagonismo em tela e as contradições de suas proximidades. Aurora, v. 12, n. 36, p. 49-64, 2020.

SACRAMENTO, Igor; MONARI, Ana Carolina Pontalti; CHEN, Xuewu. O vírus do morcego: fake news e estereotipagem dos hábitos alimentares chineses no contexto da Covid-19.

Comunicação \& Inovação, v. 21, n. 47, p. 82-98, 2020.

SANTOS, João Guilherme Bastos dos; FREITAS, Miguel; ALDÉ, Alessandra; SANTOS, Karina; CUNHA, Vanessa Cristine Cardozo. WhatsApp, política mobile e desinformação: a hidra nas eleições presidenciais de 2018. Comunicação e Sociedade, v. 41, n. 2, p. 307-334, 2019.

SISMONDO, Sergio. Post-truth?. Social Studies of Science, v. 47, n. 1, p. 3-6, 2017. 
SOARES, Felipe Bonow; RECUERO, Raquel; VOLCAN, Taiane; FAGUNDES, Giane; SODRÉ, Giéle. Research note: Bolsonaro's firehouse: How Covid-19 disinformation on WhatsApp was used to fight a government political crisis in Brazil. Harvard Kennedy School Misinformation Review, v. 2, 2021a. Disponível em: https://bit.ly/2Q7DbOV. Acesso em: 14 abr. 2021a.

SOARES, Felipe Bonow; RECUERO, Raquel; VOLCAN, Taiane; FAGUNDES, Giane; SODRÉ, Giéle. Desinformação sobre o Covid-19 no WhatsApp: a pandemia enquadrada como debate político. Ciência da Informação em Revista, v.8, n. 1, p. 74-94, 2021b. Disponível em: https://bit.ly/3jbh3PU. Acesso em: 24 jun. 2021b.

SOUZA, Juliana Lopes de Almeida; ARAÚJO, Daniel Costa de; PAULA, Diego Alves de. Mídia Social WhatsApp: uma análise sobre as interações sociais. Revista ALTERJOR, v. 1, n. 11, p. 132-165, 2015.

RECUERO, Raquel; SOARES, Felipe Bonow. O discurso desinformativo sobre a Cura do COVID-19 no Twitter: Estudo de caso. E-compós, 2020. Disponível em:

https://bit.ly/3mcMwRm. Acesso em: 7 abr. 2021.

REIS, Julio C. S.; MELO, Philipe; GARIMELLA, Kiran; BENEVENUTO, Fabrício. Can WhatsApp benefit from debunked fact-checked stories to reduce misinformation?. The Harvard Kennedy School (HKS) Misinformation Review, v. 1, n. 5, 2020. DOI: https://doi.org/10.37016/mr-2020-035

VAN LEEWEN, Theo. Legitimation in discourse and communication. Discourse and Communication, v. 1, n. 1, p. 91-112, 2007.

WARDLE, Claire; DERAKHSHAN, Hossein. Information disorder: Toward an interdisciplinary framework for research and policy making. Report. Strasbourg: Council of Europe, 2017

WODAK, Ruth. The discourse historical approach. In: WODAK, R.; MEYER, M. (Org.).

Methods of critical discourse analysis. London, England: SAGE, 2001. p. 64-94. 